\title{
Conducting fabrics of polyester coated with polypyrrole and doped with graphene oxide
}

\author{
J. Molina ${ }^{\mathrm{a}, \mathrm{b}}$, A. Zille $^{\mathrm{b}}$, J. Fernández ${ }^{\mathrm{a}}$, A.P. Souto ${ }^{\mathrm{b}}$, J. Bonastre ${ }^{\mathrm{a}}$, F. Cases ${ }^{\mathrm{a}, *}$ \\ a Departamento de Ingeniería Textil y Papelera, EPS de Alcoy, Universitat Politècnica de València, Plaza Ferrándiz y Carbonell s/n, 03801 Alcoy, Spain \\ b2C2T - Centro de Ciência e Tecnologia Têxtil, Universidade do Minho, Campus de Azurém, 4800-058 Guimarães, Portugal
}

\section{A R T I C L E I N F O}

\section{Article history:}

Received 8 January 2015

Received in revised form 26 February 2015

Accepted 18 March 2015

Available online 28 March 2015

\section{Keywords:}

Polypyrrole

Graphene oxide

Conducting fabric

X-ray photoelectron spectroscopy (XPS)

Scanning electrochemical microscopy

(SECM)

Electrochemical impedance spectroscopy

(EIS)

\begin{abstract}
A B S T R A C T
Polyester (PES) has been coated with polypyrrole (PPy) to produce conducting fabrics. Graphene oxide (GO) has been used in different concentrations (10,20 and 30\% weight) as counter ion to neutralize the positive charges of the PPy structure. Fourier transform infrared spectroscopy with attenuated total reflection (FTIR-ATR), energy dispersive X-ray (EDX) and X-ray photoelectron spectroscopy (XPS) of the $\mathrm{PPy} / \mathrm{GO}$ powders corroborated the incorporation of GO as counter ion due to the presence of $\mathrm{O}$ in the EDX spectrum, as well as an excess of $\mathrm{C}$, arising from $\mathrm{GO}$ contribution. The doping level $\left(\mathrm{N}^{+} / \mathrm{N}\right)$ decreased with the GO content. Field emission scanning electron microscopy (FESEM) showed the formation of the $\mathrm{PPy} / \mathrm{GO}$ coating and the incorporation of GO in the composite. Electrochemical impedance spectroscopy (EIS) in solid state and solution, cyclic voltammetry (CV) and scanning electrochemical microscopy (SECM) were used to test the electrical properties and electroactivity of the fabrics. There was a decrease in the electrical properties and electroactivity as the GO content increased. The conductivity of the fabrics could be tuned by varying the GO content.
\end{abstract}

(c) 2015 Elsevier B.V. All rights reserved.

\section{Introduction}

The production of fabrics with new properties has received particular attention during recent years. Different properties such as electrical conduction [1], flame resistance [2], self-cleaning [3], thermal regulation [4], color change [5], solar energy production [6], photonic [7], antimicrobial [8], UV protecting [9] or even catalysis [10] have been reported. Electrical conduction has attracted special attention in the development of antistatic or smart textiles [1].

There are different methods to produce conductive fabrics, such as the incorporation of conductive particles [11], electroless deposition of metals [12], reduced graphene oxide coatings $[13,14]$, graphene [15] or conducting polymers synthesized either chemically [16-18] or electrochemically [19,20]. During the formation of conducting polymers, positive charges are created in their structures. These charges need to be neutralized by molecules with negative charges (counter ion). Different counter ions, either organic or inorganic have been used for this purpose

\footnotetext{
* Corresponding author. Tel.: +34 966528412; fax: +34 966528438.

E-mail addresses: jamopue@doctor.upv.es (J. Molina), azille@2c2t.uminho.pt (A. Zille), jaferse1@posgrado.upv.es (J. Fernández), souto@det.uminho.pt (A.P. Souto), joboca@txp.upv.es (J. Bonastre), fjcases@txp.upv.es (F. Cases).
}

[16-18]. Here, we report the use of graphene oxide as counter ion in conducting fabrics for the first time. Graphene oxide carries a negative charge in its structure due to the presence of carboxylic acids acquiring a negative zeta potential [21]. One of the main problems of fabrics coated with conducting polymers is the migration and loss of the counter ion when the fabrics are put in solution, mainly in basic $\mathrm{pH}$ where deprotonation of PPy occurs $[17,18]$. The immobilization of a macroscopic material (between several microns and nanometers) such as graphene oxide in a conducting polymer structure prevents its solubilization. The aim of this paper is to obtain conducting fabrics of polyester coated with PPy/GO and characterize them chemically and electrochemically.

Polyester was coated with PPy and different contents of GO (10, 20 and 30\%). The chemical characterization of the PPy-GO coated fabrics was performed by FTIR-ATR, EDX and XPS. The electrical characterization of the fabrics was performed by EIS in solid state. FESEM was used to observe the morphology of the coatings and the incorporation of GO in the PPy structure. EIS in solution, CV and SECM were used to test the electroactivity of the different fabrics. PPy/GO pellets were also obtained by compacting the powder and these were analyzed by the majority of the mentioned techniques. Samples doped with an organic (AQSA) and an inorganic counter ion $\left(\mathrm{PW}_{12} \mathrm{O}_{40}{ }^{3-}\right.$ ) were also obtained and characterized by SECM for studying the effect of the counter ion's nature. 


\section{Experimental}

\subsection{Reagents and materials}

All reagents used were of analytical grade.

For the synthesis: monolayer graphene oxide (GO) powder was acquired from Nanoinnova Technologies S.L. (Spain). Analytical grade pyrrole (Py), ferric chloride $\left(\mathrm{FeCl}_{3}\right)$ and anthraquinone sulfonic acid sodium salt (AQSA) were purchased from Merck. Acetone was acquired from Prolabo. Analytical grade phosphotungstic acid $\left(\mathrm{H}_{3} \mathrm{PW}_{12} \mathrm{O}_{40}\right)$ hydrate was supplied by Fluka.

Polyester fabrics characteristics were: fabric surface density, $100 \mathrm{~g} \mathrm{~m}^{-2}$; warp threads per $\mathrm{cm}, 55$; weft threads per $\mathrm{cm}, 29$. These are specific terms used in the field of textile industry and their meaning can be consulted in a textile glossary [22].

For the characterization: sulphuric acid $\left(\mathrm{H}_{2} \mathrm{SO}_{4}\right)$ and potassium chloride $(\mathrm{KCl})$ were purchased from Merck. Hexaammineruthenium (III) chloride $\left(\mathrm{Ru}\left(\mathrm{NH}_{3}\right)_{6} \mathrm{Cl}_{3}\right)$ and iron (III) sulfate pentahydrate $\left.\left(\mathrm{Fe}_{2} \mathrm{SO}_{4}\right)_{3} \cdot 5 \mathrm{H}_{2} \mathrm{O}\right)$ were used as received from Acrōs organics.

When needed, solutions were deoxygenated by bubbling nitrogen $\left(\mathrm{N}_{2}\right.$ premier X50S). Ultrapure water was obtained from an Elix 3 Millipore-Milli-Q Advantage A10 system with a resistivity near to $18.2 \mathrm{M} \Omega \mathrm{cm}$.

\subsection{Synthesis of $P P y / G O$ on polyester fabrics}

Chemical synthesis of PPy/GO on polyester textiles was carried out similarly to previous reports [18]. Size of the samples was approximately $4 \mathrm{~cm} \times 6 \mathrm{~cm}$. Polyester was degreased with acetone before use. Pyrrole concentration employed was $2 \mathrm{gl}^{-1}(\sim 0.02 \mathrm{M})$. The molar relation of the oxidant $\left(\mathrm{FeCl}_{3}\right)$ used was $(1: 2.5)$ (pyrrole: $\mathrm{FeCl}_{3}$ ). Different concentrations of GO were used as counter ion (10, 20 and $30 \%$ respect to the pyrrole mass). The solution containing pyrrole and $\mathrm{GO}(80 \mathrm{ml})$ was placed in an ultrasound bath for $30 \mathrm{~min}$ to allow the exfoliation of the GO flakes. The second stage was the adsorption of pyrrole and GO on the PES fabric during $30 \mathrm{~min}$. After this time, the $\mathrm{FeCl}_{3}$ solution $(20 \mathrm{ml})$ was added in drops and the reaction elapsed over $150 \mathrm{~min}$ at room temperature with magnetic stirring. Adsorption and reaction elapsed in a precipitation beaker. The obtained conducting fabric was washed with water to remove unbound PPy/GO. The conducting fabrics were dried in a desiccator for at least $24 \mathrm{~h}$ before measurements were performed. Organic (AQSA) and inorganic $\left(\mathrm{PW}_{12} \mathrm{O}_{40}{ }^{3-}\right)$ molecules were also used as counter ions to compare the results obtained with those of GO. Hence, PPy/AQSA and PPy/PW $12 \mathrm{O}_{40}{ }^{3-}$ powders were obtained and collected for measuring their electrochemical behavior by SECM.

\subsection{Preparation of PPy disks}

PPy/GO, PPy/AQSA and PPy/PW $12 \mathrm{O}_{40}{ }^{3-}$ powders $(0.1 \mathrm{~g})$ were pressed in a press $(98.1 \mathrm{kN})$ to obtain discs ( $13 \mathrm{~mm}$ diameter) that were employed to carry out the different measurements.

\subsection{FTIR-ATR}

FTIR-ATR with horizontal mono-rebound attenuated total reflection accessory was performed with a Nicolet 6700 Spectrometer equipped with deuterated triglycine sulfate detector. An accessory with pressure control was used to equalize the pressure in the different solid samples. A prism of ZnSe was used and spectra were collected with a resolution of $4 \mathrm{~cm}^{-1}, 400$ scans were averaged for each sample. GO powders were characterized to assign their different contributions. PES fabrics uncoated and coated with PPy/GO (10, 20 and 30\% GO content) were characterized. In addition, PPy/GO powders (10, 20 and 30\% GO content) were also characterized.

\subsection{X-ray photoelectron spectroscopy (XPS)}

XPS measurements were performed on a VG Scientific ESCALAB200 A equipment with PISCES software for data acquisition and analysis. For analysis, an achromatic $\mathrm{Al}$ (Ka) X-ray source operating at $15 \mathrm{kV}(300 \mathrm{~W})$ was used, and the spectrometer, calibrated with reference to $\mathrm{Ag} 3 \mathrm{~d} 5 / 2(368.27 \mathrm{eV})$, was operated in CAE mode with $20 \mathrm{eV}$ pass energy. Data acquisition was performed with a pressure lower than $10^{-6} \mathrm{~Pa}$. Spectra have been charge corrected to give the adventitious $\mathrm{C} 1 \mathrm{~s}$ spectral component $(\mathrm{C}-\mathrm{C}$, $\mathrm{C}-\mathrm{H}$ ) a binding energy of $285 \mathrm{eV}$. High-resolution spectra were collected using an analysis area of $\approx 1 \mathrm{~mm}^{2}$. The peaks were constrained to have equal FWHM to the main peak. This process has an associated error of $\pm 0.1 \mathrm{eV}$. Spectra were analyzed for elemental composition using CasaXPS software (version 2.3.15). Deconvolution into sub-peaks was performed by least-squares peak analysis software, XPSPEAK version 4.1, using the Gaussian/ Lorenzian sum function and Shirley-type background subtraction. The best mixture of Gaussian-Lorentzian components was defined based on the instrument and resolution (pass energy) settings used as well as the natural line width of the specific core hole.

\subsection{Field emission scanning electron microscopy (FESEM) and energy dispersive X-ray (EDX)}

A Zeiss Ultra 55 FESEM was used to observe the morphology of the samples using an acceleration voltage of $3 \mathrm{kV}$. Energy dispersive X-ray (EDX) measurements were performed between 0 and $10 \mathrm{kV}$.

\subsection{Electrical characterization by electrochemical impedance spectroscopy (EIS)}

An Autolab PGSTAT302 potentiostat/galvanostat was used to perform EIS analyses. EIS measurements were performed in the $10^{5}-10^{-2} \mathrm{~Hz}$ frequency range. The amplitude of the sinusoidal voltage used was $\pm 10 \mathrm{mV}$. Measurements were carried out in a two-electrode arrangement, in which the sample was located between two round copper electrodes $\left(A=1.33 \mathrm{~cm}^{2}\right)$. In the second configuration, two rectangular copper electrodes $(0.5 \mathrm{~cm} \times 1.5 \mathrm{~cm})$ separated by $1.5 \mathrm{~cm}$ and pressed on the fabric sample were used. The measured area of the fabric with this configuration was a square of $1.5 \mathrm{~cm}$ so the measured impedance modulus $(\Omega)$ was equal to the surface resistivity $(\Omega / \square)[19,20]$.

\subsection{Electrochemical impedance spectroscopy (EIS) measurements in solution}

A standard three-electrode design was used to measure the EIS response of PES-PPy/GO samples in $0.1 \mathrm{M} \mathrm{H}_{2} \mathrm{SO}_{4}$ solutions. An asymmetrical configuration metal/sample/electrolyte was used. The sample was mounted on a stainless steel plate (used to produce the electrical connection). An $\mathrm{Ag} / \mathrm{AgCl}(3.5 \mathrm{M} \mathrm{KCl})$ electrode and stainless steel rod were used as reference electrode and counter electrode, respectively. The effective area used was $0.28 \mathrm{~cm}^{2}$.

The experimental results were also fitted using a non-linear least squares fitting minimization method by ZView software (version 2.7).

\subsection{Cyclic voltammetry (CV) measurements}

An Autolab PGSTAT302 potentiostat/galvanostat was used to perform CV measurements in $0.1 \mathrm{M} \mathrm{H}_{2} \mathrm{SO}_{4}$ medium. To produce the electrical contact with the fabrics, they were located between two Ti plates. The measurements were performed in a three-electrode 
arrangement. A Pt wire was used as counter electrode and its preparation consisted of a flame treatment to clean its surface prior to carrying out the synthesis, according to the method developed by Clavilier [23]. The working electrode was made by cutting a strip of the conducting fabrics. Potential measurements were referred to $\mathrm{Ag} / \mathrm{AgCl}(3.5 \mathrm{M} \mathrm{KCl})$ reference electrode. Oxygen was removed from solution by bubbling nitrogen gas for $15 \mathrm{~min}$ and then an $\mathrm{N}_{2}$ atmosphere was maintained during the measurements. The ohmic potential drop was measured and introduced in the Autolab software (GPES). The measurements were taken between $-0.2 \mathrm{~V}$ and $0.7 \mathrm{~V}$ at different scan rates $\left(50,5\right.$ and $\left.1 \mathrm{mV} \mathrm{s}^{-1}\right)$.

\subsection{Scanning electrochemical microscopy (SECM)}

SECM measurements were carried out with a scanning electrochemical microscope of Sensolytics. A three-electrode configuration cell consisting of a 25 or $100-\mu$ m-diameter Pt microelectrode, a Pt wire auxiliary electrode and an $\mathrm{Ag} / \mathrm{AgCl}$ (3.5 M $\mathrm{KCl})$ reference electrode. Measurements were performed in $\mathrm{Ru}$ $\left(\mathrm{NH}_{3}\right)_{6}{ }^{3+} 0.01 \mathrm{M}$ and $0.1 \mathrm{M} \mathrm{KCl}$ (supporting electrolyte). All the experiments were carried out in an inert nitrogen atmosphere. The substrates were samples $\left(0.5 \mathrm{~cm}^{2}\right)$ cut from the different fabrics PES-PPy/GO (10\%), PES-PPy/GO (20\%), PES-PPy/GO (30\%). Additional measurements were also performed on the conductive fabrics with another redox mediator $\left(0.01 \mathrm{M} \mathrm{Fe}^{3+}\right.$ in $0.5 \mathrm{M} \mathrm{H}_{2} \mathrm{SO}_{4}$ solutions). In this case the microelectrode employed was the 100 $\mu$ m-diameter one.

Disks of PPy/AQSA, PPy/PW $12 \mathrm{O}_{40}{ }^{3-}$ and PPy/GO powders with different GO contents (10, 20 and 30\%) were also analyzed by SECM. In this case, the microelectrode used was the $25-\mu \mathrm{m}$ diameter one, since the disk sample was flat and smooth.

The samples (either fabrics or powder disks) were glued to microscope slides with epoxy resin. The microelectrode operated at a potential of $-0.4 \mathrm{~V} \mathrm{Ru}\left(\mathrm{NH}_{3}\right)_{6}{ }^{3+}$, or $-0.1 \mathrm{~V}\left(\mathrm{Fe}^{3+}\right)$ at which the oxidized form of the redox mediator $(\mathrm{Ox})$ is reduced (Red) at diffusion controlled rate. Approach curves were obtained by recording the tip reduction current as the Pt microelectrode tip was moved in $\mathrm{z}$ direction. Approach curves give us an indication of the electroactivity of the surface. These curves were compared to the theoretical ones (positive and negative feedback models). The substrate's surface in all the measurements were at their open circuit potential (OCP).

\section{Results and discussion}

\subsection{FTIR-ATR characterization}

Fig. 1 shows the FTIR characterization of GO and PPy-GO powders with different GO contents (10, 20 and 30\%). The band around $1540 \mathrm{~cm}^{-1}$ was associated to the pyrrole ring stretching vibration $(\mathrm{C}=\mathrm{C})$. $\mathrm{C}-\mathrm{C}$ stretching vibration can be observed at $1450 \mathrm{~cm}^{-1}$. The band at $1300 \mathrm{~cm}^{-1}$ was attributed to $\mathrm{C}-\mathrm{N}$ stretching vibration. The characteristic bands of the bending vibration of pyrrole can be observed at 775, 1037 and $1162 \mathrm{~cm}^{-1}$ $[16,24]$. The band at $1092 \mathrm{~cm}^{-1}$ was attributed to the $\mathrm{N}^{+}-\mathrm{H}$ in plane deformation. The band at $956 \mathrm{~cm}^{-1}$ was attributed to $\mathrm{C}-\mathrm{C}$ out of plane deformation. The band at $890 \mathrm{~cm}^{-1}$ was ascribed to $\mathrm{C}_{\beta}-\mathrm{H}$ out of plane vibration [24]. The band at $842 \mathrm{~cm}^{-1}$ was ascribed to $\mathrm{C}-\mathrm{H}$ rocking [25]. There was little variation of the different PPy bands with the GO content.

The spectrum of GO powders is also presented as reference. The main features are: the band around $1720 \mathrm{~cm}^{-1}$ which was ascribed to stretching vibrations from $\mathrm{C}=\mathrm{O}$. The peak at $1613 \mathrm{~cm}^{-1}$ arises from $\mathrm{C}=\mathrm{C}$ from unoxidized $\mathrm{sp}^{2}$ bonds. The band at $1220 \mathrm{~cm}^{-1}$ was ascribed to $\mathrm{C}-\mathrm{OH}$ stretching vibrations, and finally the band around $1050 \mathrm{~cm}^{-1}$ was attributed to $\mathrm{C}-\mathrm{O}$ stretching vibrations

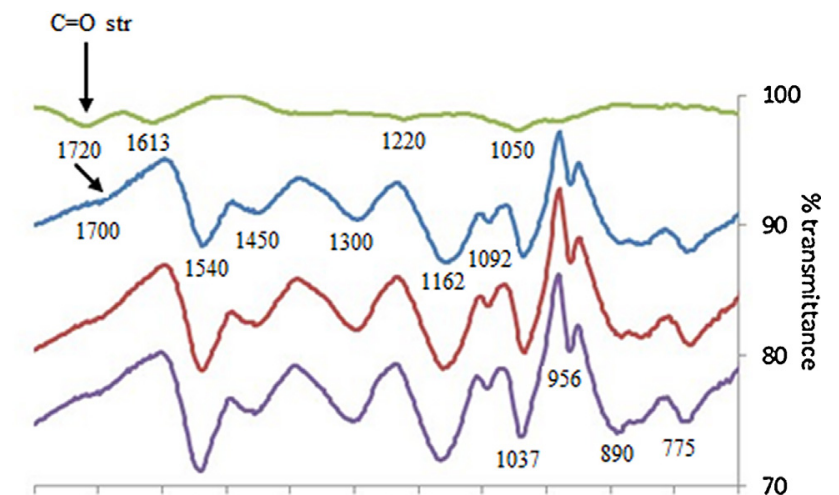

180017001600150014001300120011001000900800700 Wavenumbers $\left(\mathrm{cm}^{-1}\right)$

$-\mathrm{PPy} / \mathrm{GO}(10 \%)-\mathrm{PPy} / \mathrm{GO}(20 \%)-\mathrm{PPy} / \mathrm{GO}(30 \%)-\mathrm{GO}$

Fig. 1. FTIR-ATR spectra of GO powders, and PPy/GO powders (10, 20 and $30 \% \mathrm{GO}$ content). Resolution $4 \mathrm{~cm}^{-1}$, 400 scans.

[13]. In the PPy/GO spectra, the presence of a band around $1700 \mathrm{~cm}^{-1}$ is the evidence of the presence of GO. This band corresponds to $\mathrm{C}=\mathrm{O}$ stretching vibrations and suffered a displacement to lower wavenumbers due to the $\pi-\pi$ interactions and hydrogen bonding between polypyrrole rings and GO sheets [26].

Fig. 2 shows the characterization spectra of polyester fabrics, the most representative bands are: $720 \mathrm{~cm}^{-1}$ (out of plane benzene group), $960 \mathrm{~cm}^{-1}$ (C - O stretching of glycol), $1014 \mathrm{~cm}^{-1}$ (in-plane vibration of benzene), $1090 \mathrm{~cm}^{-1}$ (ester $\mathrm{C}=\mathrm{O}$ stretching), $1236 \mathrm{~cm}^{-1}$ (ester $\mathrm{C}=\mathrm{O}$ stretching) and $1714 \mathrm{~cm}^{-1}(\mathrm{C}=\mathrm{O}$ stretching of aromatic ester) [27]. When PES fabrics were coated with the different PPy/GO coatings, the removal of the different PES bands and the appearance of the different PPy bands that were described in Fig. 1 could be observed. The presence of the band around $1700 \mathrm{~cm}^{-1}$ and attributed to $\mathrm{C}=\mathrm{O}$ stretching vibration in $\mathrm{GO}$ is also worth highlighting [26]. The PPy/GO layer is thick enough to avoid the penetration of the IR radiation until the PES substrate and hence PES bands are hardly observed.

\subsection{FESEM and EDX}

Fig. 3 shows the characterization of the different PPy/GO coatings on PES by SEM. Fig. 3a shows the original PES fabric. As can be seen, the surface of the fibers is quite smooth with no mentionable features. Fig. 3b shows the PES-PPy/GO (10\%) sample. It can be seen that the fibers are coated with a continuous PPy layer. In addition, the formation of PPy/GO aggregates on the surface of

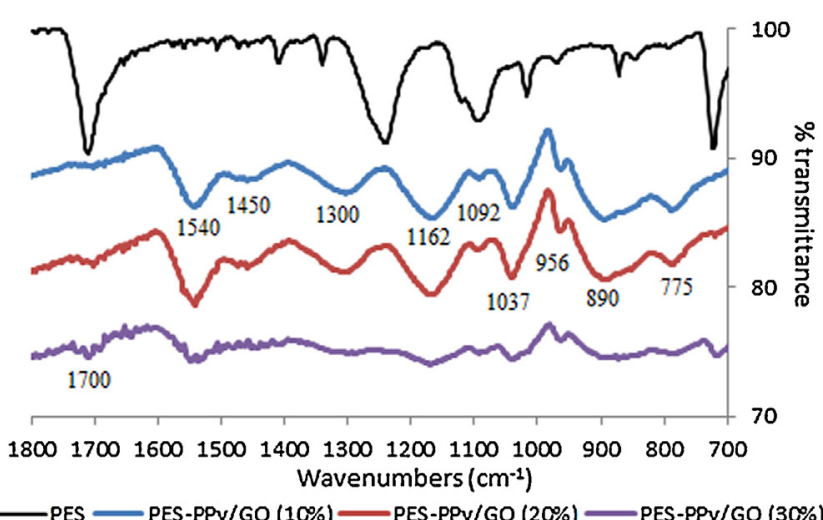

Fig. 2. FTIR-ATR spectra of PES fabrics and PES fabrics coated with PPy/GO (10, 20 and $30 \%$ GO content). Resolution $4 \mathrm{~cm}^{-1}, 400$ scans. 

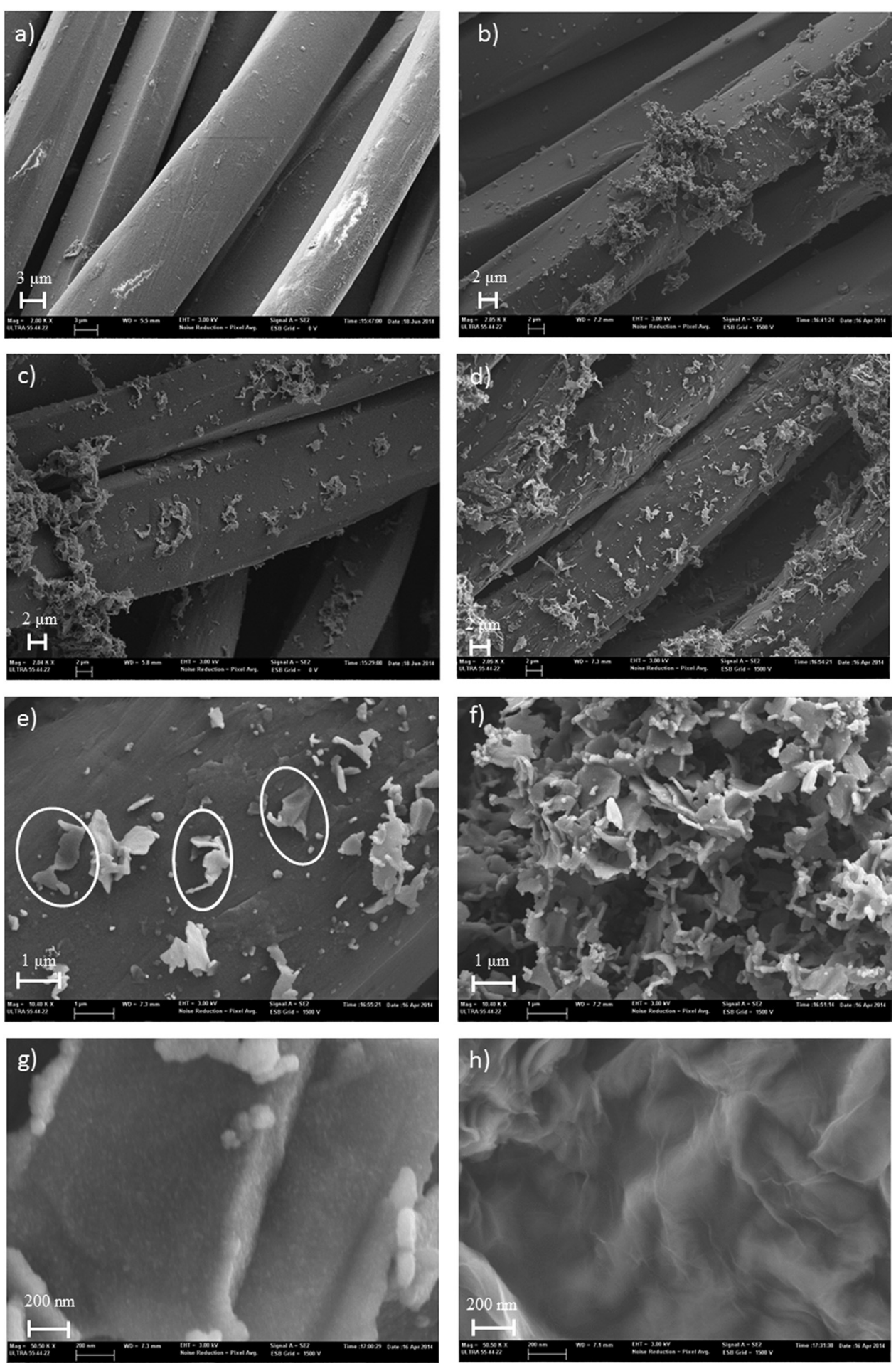

Fig. 3. FESEM micrographs of (a) PES ( $x 2$ K), (b) PES-PPy/GO (10\%) (x2 K), (c) PES-PPy/GO (20\%) (x2 K), (d) (e) (f) (g) PES-PPy/GO (30\%) (x2 K) (x10 K) (x10 K) (x50 K), (h) GO (x50 K).

the fibers can also be observed. When the GO content was increased to 20\% (Fig. 3c) and 30\% (Fig. 3d), there was not a substantial modification of the morphology. However, an increase in the GO sheets content on the fibers could be easily observed. In Fig. 3e, the surface of the fiber coated with PES-PPy/GO (30\%) is magnified for better observation. In this micrograph the incorporation of GO sheets in the PPy coating can be seen. Some GO sheets are trapped in the polymer structure (the sheets have been circled for easy observation). Fig. 3f shows the magnification of PPy/GO aggregates in a zone where they were observed on the surface of the fibers. The GO sheets can be clearly observed on the micrograph. All the sheets are coated with a continuous layer of PPy. Fig. 3g shows the magnification of a GO sheet coated with PPy nanoparticles [28] that agglomerate and form globular morphology. Fig. $3 \mathrm{~h}$ shows the morphology of a GO sheet prior to performing the PPy polymerization for comparison; GO sheet shows the characteristic wrinkles [29] that help to locate them on the surface of the fibers [13]. The wrinkles are no longer observed after PPy 
a)
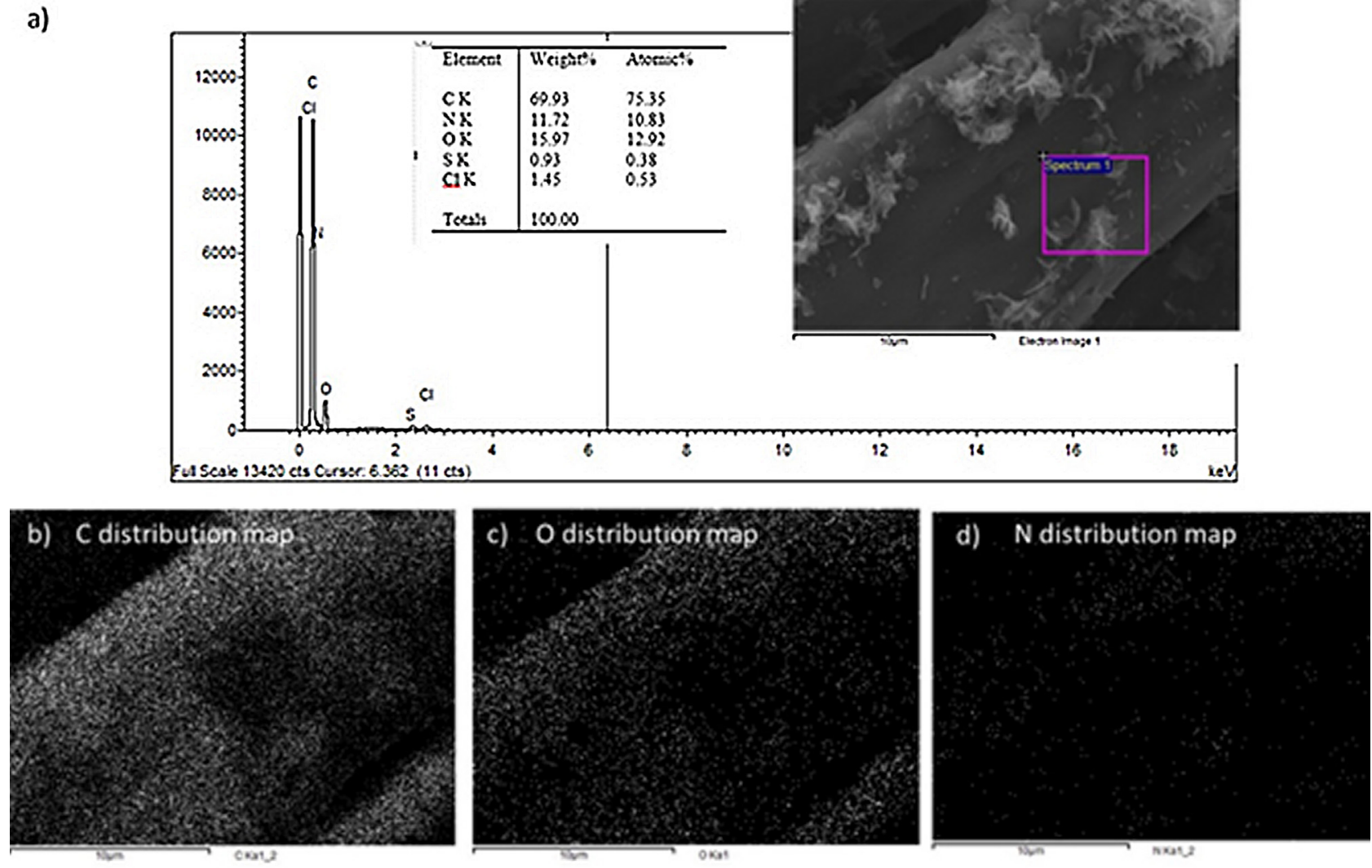

Fig. 4. (a) EDX spectra and (b) C, (c) O and (d) N distribution element maps of the PES-PPy/GO (30\%) sample.

deposition since the PPy film is thick enough to avoid observation. More work is in progress to evaluate the rubbing and washing fastness as well as its improvement by plasma technique treatments.

An EDX analysis was performed on the surface of the PES-PPy/ GO (30\%) sample as example (Fig. 4a). The most remarkable elements are $\mathrm{C}, \mathrm{O}$ and $\mathrm{N}$. Carbon arises from pyrrole $\left(\mathrm{C}_{4} \mathrm{H}_{5} \mathrm{~N}\right)$ and graphene oxide. Nitrogen arises from pyrrole units. And the source of oxygen is mainly graphene oxide. Taking into account the atomic nitrogen content obtained (10.83\%), the carbon content arising from polypyrrole was calculated (43.32\%). The source for the rest of the carbon (32.03\%) corresponds to graphene oxide. The $\mathrm{O} / \mathrm{C}$ (32.03/10.83) ratio obtained was 0.4 ; which is in agreement with previous results obtained [14]. The presence of sulfur arises from the synthesis method employed to obtain graphene oxide powders which employs sulfuric acid among other strong acids and oxidants [30].

Carbon, oxygen and nitrogen distribution maps were performed to see the local distribution of these elements on the surface of the PES-PPy/GO (30\%) sample (Fig. 4b, c and d, respectively). The analyses were performed with FESEM, where no additional coating was applied on the surface of the samples. Oxygen is well distributed on the surface of the fiber, which indicates that GO has been incorporated in the PPy structure. Nitrogen arising from PPy was also well distributed on the surface of the fibers which indicates a uniform deposition of PPy.

\subsection{X-ray photoelectron spectroscopy (XPS)}

The relative chemical composition $(\mathrm{C}, \mathrm{N}, \mathrm{O}$ and $\mathrm{Cl})$ and atomic ratios $(\mathrm{O} / \mathrm{C}$ and $\mathrm{N} / \mathrm{C}$ ) of the polypyrrole (PPy) powders synthetized with different GO concentrations as counter ion (10, 20 and $30 \%$ wt) and the polyester (PES) fabric coated with the PPy/GO composite were analyzed by XPS (Table 1 ). In the PPy/GO powders, the presence of different concentration of GO leads to significant differences in the atomic $\mathrm{O} / \mathrm{C}$ and N/C, especially for $30 \% \mathrm{wt}$ of GO. In the presence of $30 \% \mathrm{wt}$ of $\mathrm{GO}$, the $\mathrm{O} / \mathrm{C}$ ratio is an order of magnitude higher compared to 10 and $20 \%$ wt. These results, in addition to the significant decrease of the $\mathrm{N} / \mathrm{C}$ ratio for the $30 \% \mathrm{wt}$ of GO, indicate a lower polypyrrole content in this sample. The fraction of powders analyzed seem to have a higher GO content and lower PPy one. The growth of PPy takes place progressively on the surface of the fabric. Positive charges are created in the structure of the polymer and they are neutralized by the negative charges provided by GO. The growth continues till the monomer is exhausted or the polymerization process is stopped. At the same time, the excess of GO and Py (pyrrole) react in solution and produce the PPy/GO powders. In the case of the PPy powders containing the $30 \% \mathrm{GO}$, it seems that the quantity of GO is excessive and the quantity of PPy on the GO sheets is lower than with the other GO contents ( 10 and 20\%). This does not happen in the case of the fabric, where GO is progressively incorporated as the film

Table 1

Relative chemical composition (At\%) and atomic ratio determined by XPS of PPy/GO powders $(10,20,30 \%$ of GO content) and PPy/GO coated on PES fabrics $(10,20,30 \%$ of GO content).

\begin{tabular}{|c|c|c|c|c|c|c|}
\hline & \multicolumn{3}{|c|}{ PPy/GO powders } & \multicolumn{3}{|c|}{ PPy/GO coated on PES fabrics } \\
\hline & GO (10\%) & GO (20\%) & GO (30\%) & GO (10\%) & GO (20\%) & GO (30\%) \\
\hline $\mathrm{C} 1 \mathrm{~s}$ & 69.64 & 71.31 & 43.05 & 73.86 & 73.67 & 68.56 \\
\hline N1s & 12.41 & 14.30 & 3.53 & 13.54 & 13.15 & 11.54 \\
\hline 01s & 14.36 & 11.20 & 49.88 & 10.02 & 10.93 & 17.78 \\
\hline $\mathrm{Cl} 2 \mathrm{p}$ & 3.58 & 3.19 & 3.54 & 2.59 & 2.26 & 2.12 \\
\hline $\mathrm{O} / \mathrm{C}$ & 0.21 & 0.16 & 1.16 & 0.14 & 0.15 & 0.26 \\
\hline $\mathrm{N} / \mathrm{C}$ & 0.18 & 0.20 & 0.08 & 0.18 & 0.18 & 0.17 \\
\hline
\end{tabular}


Table 2

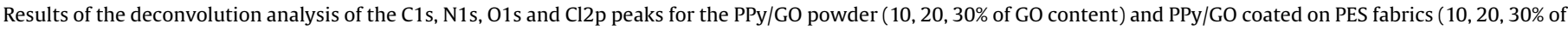
GO content).

\begin{tabular}{|c|c|c|c|c|c|c|c|c|c|c|c|c|c|c|c|c|c|c|}
\hline & \multicolumn{18}{|c|}{ Relative area corresponding to different chemical bonds (\%) } \\
\hline & \multicolumn{7}{|c|}{$\mathrm{C} 1 \mathrm{~s}(\mathrm{eV})$} & \multicolumn{5}{|c|}{ O1s $(e V)$} & \multicolumn{2}{|c|}{$\mathrm{N} 1 \mathrm{~s}(\mathrm{eV})$} & \multicolumn{4}{|c|}{$\mathrm{Cl} 2 \mathrm{p}(\mathrm{eV})$} \\
\hline & 284.6 & 285.0 & 285.5 & 286.7 & 287.1 & 288.5 & 291.0 & 530.6 & 531.8 & 532.0 & 533.4 & 535.5 & 400.1 & 401.7 & 197.5 & 198.8 & 200.3 & 202.0 \\
\hline PPy/GO (10\%) & 43.2 & - & 32.3 & - & 12.6 & 9.2 & 2.7 & 19.4 & - & 57.4 & 19.8 & 3.3 & 86.6 & 13.4 & 35.5 & 37.2 & 22.4 & 4.8 \\
\hline PPy/GO (20\%) & 46.5 & - & 27.8 & - & 14.6 & 8.3 & 2.9 & 29.6 & - & 38.8 & 28.1 & 3.4 & 87.3 & 12.7 & 37.1 & 30.8 & 22.8 & 9.3 \\
\hline PPy/GO (30\%) & 54.3 & - & 22.8 & - & 12.2 & 10.7 & - & 39.5 & - & 50.0 & 9.1 & 1.4 & 90.9 & 9.1 & - & 68.1 & 31.9 & - \\
\hline PES-PPy/GO (10\%) & - & 71.1 & - & 16.1 & - & 10.8 & 2.0 & - & 63.1 & - & 36.9 & - & 88.7 & 11.3 & 49.3 & 32.4 & 12.8 & 5.4 \\
\hline PES-PPy/GO (20\%) & - & 68.9 & - & 16.8 & - & 11.8 & 2.5 & - & 66.6 & - & 33.4 & - & 87.3 & 12.7 & 51.3 & 33.6 & 11.2 & 3.9 \\
\hline PES-PPy/GO (30\%) & - & 65.9 & - & 16.5 & - & 15.7 & 1.9 & - & 78.7 & - & 21.3 & - & 89.2 & 10.8 & 34.9 & 34.8 & 22.6 & 7.7 \\
\hline
\end{tabular}

grows to compensate the positive charges created in the structure of the polymer.

On the other hand, the coated PES fabrics show only a two-fold increase in the $\mathrm{O} / \mathrm{C}$ ratio in the composite with $30 \%$ wt of $\mathrm{GO}$ without significant changes in the N/C ratio. These results could indicate uniform deposition of the PES-PPy/GO composite on the fibers surface and confirm that GO has been uniformly incorporated in the PPy structure.

The C1s spectra of the PPy/GO nanocomposite powders can be deconvoluted in four peaks (Fig. S1a, b and c) centered at 284.6, 285.5, 287.1 and $288.5 \mathrm{eV}$ attributed to the $\mathrm{C}-\mathrm{C}, \mathrm{C}-\mathrm{N}, \mathrm{C}-\mathrm{OH} / \mathrm{C}=\mathrm{O}$, and $\mathrm{O}-\mathrm{C}=\mathrm{O}$, respectively [14,31]. A fifth satellite peak at $291 \mathrm{eV}$ is attributed to the $\mathrm{C} 1 \mathrm{~s}$ shake-up [32]. The C1s spectra exhibit a decrease of the carbon binding to nitrogen as function of the GO content, which is associated to the lowering of PPy in the composite (Table 2). At the same time, the increase in intensity of the peak associated with the $\mathrm{C}-\mathrm{C}$ component and with the carbons binding to oxygen (especially the $\mathrm{O}-\mathrm{C}=\mathrm{O}$ ) confirms the incorporation of GO in the polymer matrix [31,33]. It was not possible to separate the contributions of $\mathrm{C}-\mathrm{O}$ and $\mathrm{C}=\mathrm{O}$ peaks in the $\mathrm{C} 1 \mathrm{~s}$ region that was deconvoluted in a unique peak at $287.1 \mathrm{eV}$.

The $\mathrm{C} 1 \mathrm{~s}$ envelope of the PES-PPy/GO nanocomposite can be deconvoluted in three peaks (Fig. S1 d, e and f) centered at 285, 286.7 and $288.5 \mathrm{eV}$ attributed to the $\mathrm{C}-\mathrm{C} / \mathrm{C}-\mathrm{N}, \mathrm{C}-\mathrm{OH}$, and $\mathrm{O}-\mathrm{C}=\mathrm{O}$, respectively. A fourth satellite peak at $291 \mathrm{eV}$ is attributed to the $\mathrm{C} 1 \mathrm{~s}$ shake-up [32]. No separate deconvolution was possible between the $\mathrm{C}-\mathrm{C}$ and $\mathrm{C}-\mathrm{N}$ component peaks and a unique peak centered at $285 \mathrm{eV}$ was reported, suggesting a uniform incorporation of GO in the PPy structure on the coated PES [34]. The C-C/ $\mathrm{C}-\mathrm{N}$ component decreases to lower values (from $71 \%$ to $65 \%$ ) as a function of the GO content, due to the lowering on the $\mathrm{C}-\mathrm{N}$ component of the PPy structure.

Supplementary material related to this article found, in the online version, at http://dx.doi.org/10.1016/j.synthmet.2015. 03.014 .

Interestingly, the peak previously observed at $287.1 \mathrm{eV}$ shifted to a lower value at $286.7 \mathrm{eV}$ attributed to the presence of carbon single bonded to oxygen. However, no significant change in percentage of this component was observed in presence of different concentrations of GO. The overestimation of the $\mathrm{C}-\mathrm{O}$ groups from $\mathrm{C} 1 \mathrm{~s}$ fitting could be due to the presence of the satellite component related to the electronic structure of PPy as previously observed [35]. The increase from $11 \%$ to $16 \%$ of the peak related to the $\mathrm{O}-\mathrm{C}=\mathrm{O}$ functionalities at $288.5 \mathrm{eV}$ suggests that in the $\mathrm{PPy} / \mathrm{GO}$ coated on the PES fibers the component of the carbons double bonded to oxygen had undergone chemical changes due to better incorporation of the two components in the nanocomposite [31].

In order to understand the different contribution of the single and double bonded oxygen in the nanocomposite synthesis, the O1s region was also analyzed. The 01s XPS spectra of PPy/GO powders are illustrated in Fig. S2 ( $a, b$ and $c$ ), which is deconvoluted into three peaks. The peaks at 530.6, 532 and $533.4 \mathrm{eV}$ are ascribed to $\mathrm{O}-\mathrm{C}=\mathrm{O}, \mathrm{C}=\mathrm{O}$ and $\mathrm{C}-\mathrm{O}-\mathrm{C} / \mathrm{C}-\mathrm{OH}$, respectively [36]. As observed before in the $\mathrm{C} 1 \mathrm{~s}$ spectra, the $\mathrm{C}-\mathrm{O}$ and $\mathrm{C}=\mathrm{O}$ components of the $\mathrm{PPy} / \mathrm{GO}$ powders show discrepancies in the oxygen species in function of the GO content, confirming the presence of agglomerates. The increase in the carboxylic groups (from $19.4 \%$ to $39.5 \%$ ) demonstrated the high level of oxidation due to the presence of increasing amount of GO in the PPy structure.

Supplementary material related to this article found, in the online version, at http://dx.doi.org/10.1016/j.synthmet.2015. 03.014.

The BE values for O1s in the PES-PPy/GO (Fig. S2d, e and f) nanocomposite components confirm, once again, the uniform incorporation of GO in the PPy structure coated on PES. Coherence between the independent fittings of $\mathrm{C} 1 \mathrm{~s}$ and $\mathrm{O} 1 \mathrm{~s}$ signals was observed. The double bonded oxygen components can be
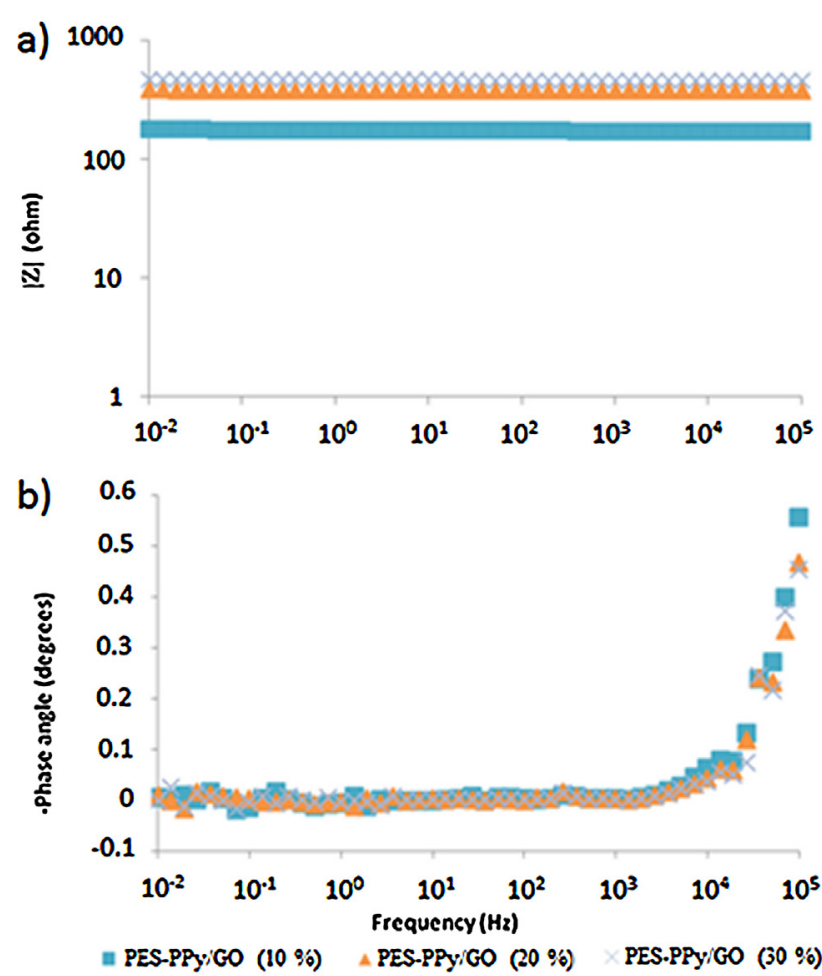

Fig. 5. Bode plots for PES-PPy/GO (10\%), PES-PPy/GO (20\%) and PES-PPy/GO (30\%). Measurements between two copper electrodes above the samples. Distance between electrodes $1.5 \mathrm{~cm}$. Textile measured area $1.5 \mathrm{~cm} \times 1.5 \mathrm{~cm}$. Frequency range from $10^{5} \mathrm{~Hz}$ to $10^{-2} \mathrm{~Hz}$. (a) |Z| vs. frequency plot, (b)-phase angle vs. frequency plot. 

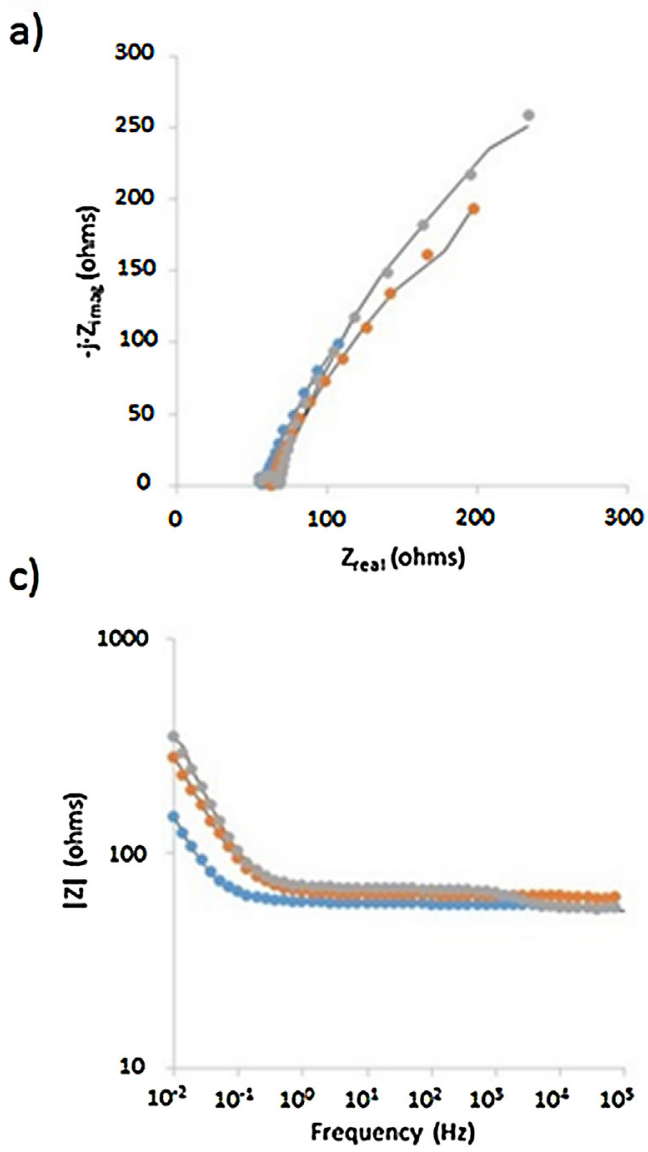

b)

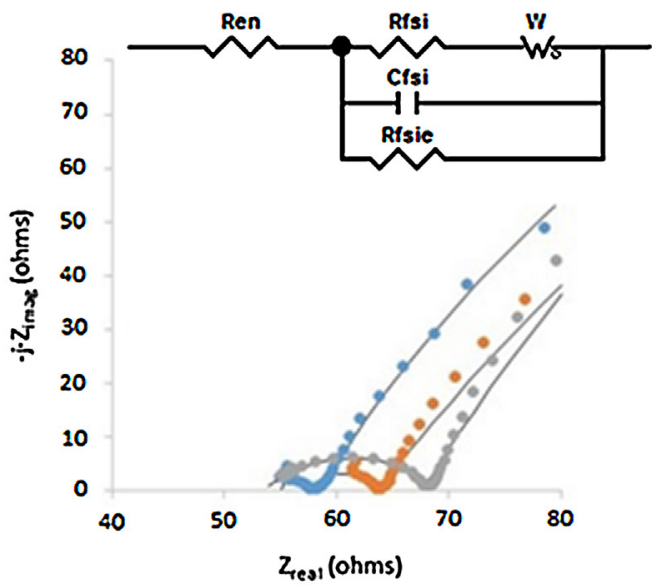

d)

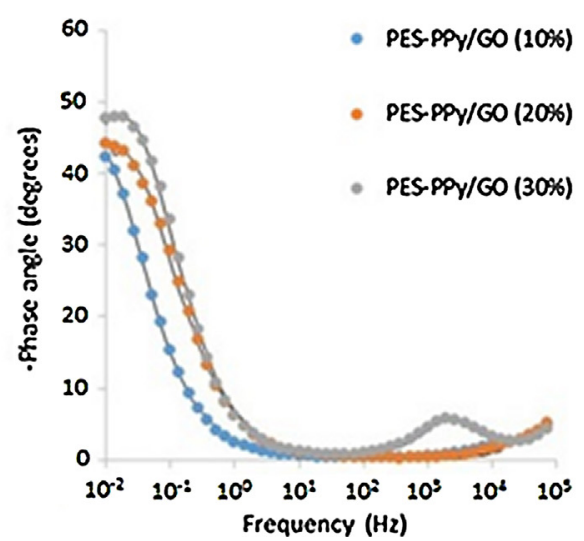

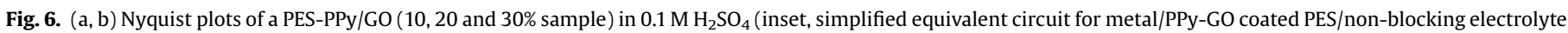

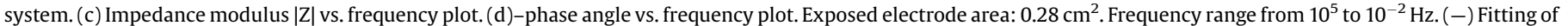
experimental data.

deconvoluted in a single peak at $531.8 \mathrm{eV}$, which increases with the increase of GO in the coating, confirming the conversion of the $\mathrm{C}=\mathrm{O}$ and $\mathrm{O}=\mathrm{C}-\mathrm{OH}$ groups to a new chemical species in the uniformly dispersed nanocomposite. At the same time, the peak at $533.4 \mathrm{eV}$ of $\mathrm{C}-\mathrm{O}$ (epoxy and alkoxy) decreases noticeably, indicating that these functional groups are partially removed [37].

In the N1s XPS core-level spectra (Fig. S3), the peak at $400.1 \mathrm{eV}$ is attributed to the neutral and amine-like structure $(\mathrm{C}-\mathrm{N}, \mathrm{N}-\mathrm{H})$. The spectra do not show the peak at 398.3 attributed to quinonoid imine $(=\mathrm{N}-)$, which indicates that the PPy composites prepared present few defects [38]. Conversely, the peak at $401.7 \mathrm{eV}$ is due to the positively charged nitrogen atoms with protonation $\left(\mathrm{N}-\mathrm{H}^{+}\right)$ and is correlated with the doping level $\left(\mathrm{N}^{+} / \mathrm{N}\right)$ of the composite [39]. In both the powder and PES coated PPy/GO nanocomposites, the doping level decreases with the addition of GO. The decrease of the doping level indicates a lower conductivity of the samples. This was confirmed by electrical measurements performed by EIS.

Supplementary material related to this article found, in the online version, at http://dx.doi.org/10.1016/j.synthmet.2015. 03.014.
The deconvoluted $\mathrm{Cl} 2 \mathrm{p}$ spectra (Fig. S4) show four peaks centered at 197.5, 198.8, 200.3 and $202 \mathrm{eV}[40,41]$. The first peak with the lowest BE corresponds to chlorine in the ionic form $\left(\mathrm{Cl}^{-}\right.$ anion), while the other is indicative of intermediate chlorine species $\left(\mathrm{Cl}^{*}\right)$ due to a charge transfer between the polypyrrole backbone and the chloride [42]. This indicates a partial doping from chloride species. The two peaks located at $200.3 \mathrm{eV}\left(2 \mathrm{p}_{3 / 2}\right)$ and $202 \mathrm{eV}\left(2 \mathrm{p}_{1 / 2}\right)$ are attributed to covalent chloride $(\mathrm{C}-\mathrm{Cl})$ $[43,44]$.

Supplementary material related to this article found, in the online version, at http://dx.doi.org/10.1016/j.synthmet.2015. 03.014.

\subsection{Electrical characterization by EIS}

EIS technique was used to measure the electrical properties of the conductive fabrics. The impedance modulus $|\mathrm{Z}|$ was used to measure the electrical resistance of the samples. The phase angle was used as an indication of the conductive/insulating behavior of the samples.

Table 3

Results of the fitting of impedance data of PES-PPy/GO (10, 20 and 30\% GO) in $0.1 \mathrm{M} \mathrm{H}_{2} \mathrm{SO}_{4}$ solution.

\begin{tabular}{|c|c|c|c|c|c|c|c|c|}
\hline & Chi-sqr & $\operatorname{Ren}(\Omega)$ & $\operatorname{Rfsi}(\Omega)$ & $\mathrm{W}-\mathrm{R}(\Omega)$ & W-T (s) & W-P & Cfsi (F) & Rfsie $(\Omega)$ \\
\hline PES-PPy/GO (10\%) & 0.0038 & 53.63 & 3.963 & 2.651 & 0.15 & 0.41 & $1.41 \times 10^{-6}$ & 601 \\
\hline PES-PPy/GO (20\%) & 0.0043 & 56.88 & 6.72 & 1402 & 120.50 & 0.77 & $3.77 \times 10^{-7}$ & 815 \\
\hline PES-PPy/GO (30\%) & 0.0043 & 55.06 & 12.61 & 1973 & 116.00 & 0.81 & $5.92 \times 10^{-6}$ & 1082 \\
\hline
\end{tabular}


a)

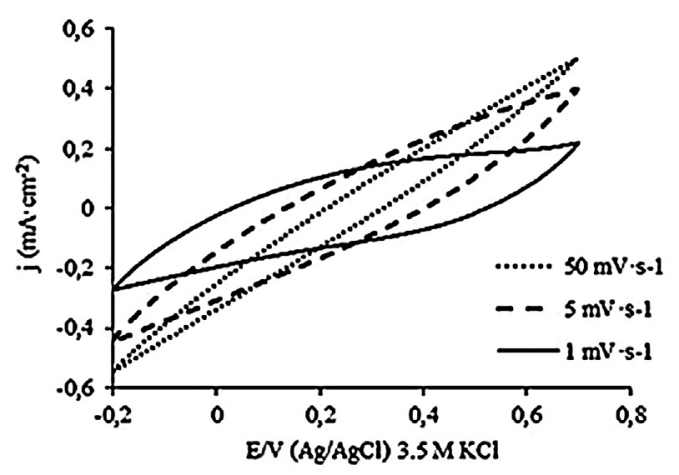

b)

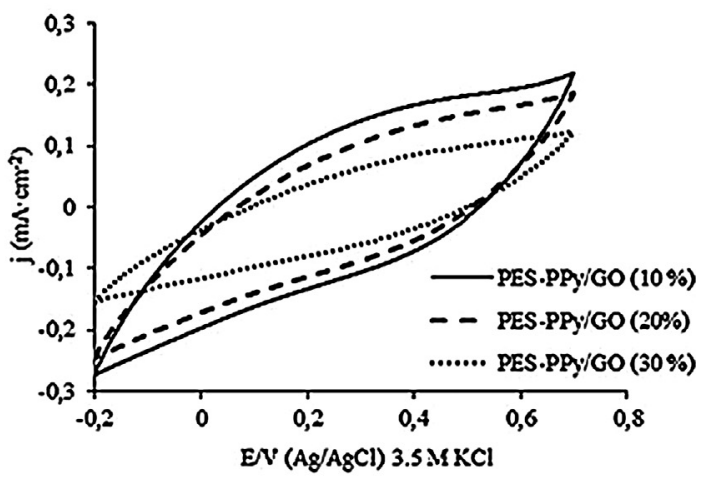

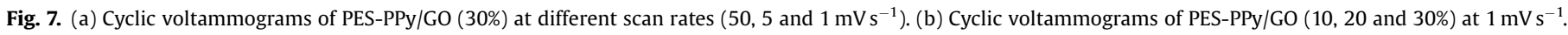
Second scan for all measurements.

Fig. S5 shows the Bode plots for the samples of PES-PPy/GO (10\%), PES-PPy/GO (20\%) and PES-PPy/GO (30\%), the averaged values of impedance modulus obtained were $0.45 \Omega, 0.47 \Omega$ and $1.09 \Omega$, respectively. There was an increase in the resistance of the fabrics with the increasing GO content. The -phase angle also showed values near to $0^{\circ}$ for all the samples. A value of -phase angle of $0^{\circ}$ indicates that the samples behave like a resistive material (conducting material). On the other hand, values of $90^{\circ}$ would indicate a capacitive behavior (insulating material).

Supplementary material related to this article found, in the online version, at http://dx.doi.org/10.1016/j.synthmet.2015. 03.014 .

Sheet resistance of the fabrics was obtained with the second electrode configuration, where two rectangular copper electrodes $(0.5 \mathrm{~cm} \times 1.5 \mathrm{~cm})$ separated by $1.5 \mathrm{~cm}$ and pressed on the fabric sample were used. The measured area of the fabric with this configuration was a square of $1.5 \mathrm{~cm}$ so the measured impedance modulus $(\Omega)$ was equal to the surface resistivity $(\Omega / \square)[19,20]$. The different values of surface resistivity obtained for the samples of PES-PPy/GO (10\%), PES-PPy/GO (20\%) and PES-PPy/GO (30\%) were $177 \Omega / \square, 385 \Omega / \square, 472 \Omega / \square$, respectively (Fig. 5). The -phase angle was also near to $0^{\circ}$, indicating a pure resistive behavior. There was an increase of impedance modulus and sheet resistance with the GO content. The increase of resistance with the increasing GO content is in accordance with the XPS results, where a decrease of the doping level $\left(\mathrm{N}^{+} / \mathrm{N}\right)$ was also observed.

The fabrics obtained could be used as antistatic materials since static charging of the fibers is excluded for sheet resistance below $5 \times 10^{9} \Omega / \square[45]$. The values of surface resistivity obtained when employing an organic (AQSA) or inorganic $\left(\mathrm{PW}_{12} \mathrm{O}_{40}{ }^{3-}\right.$ ) counter ions were $45 \Omega / \square$ and $250 \Omega / \square$, respectively [17,18]. The planar structure of the counter ion AQSA allows a better arrangement of PPy chains than the 3-D molecules of $\mathrm{PW}_{12} \mathrm{O}_{40}{ }^{3-}$ [16]. The conductivity of the samples containing $10 \%$ GO was near to that obtained with the inorganic counter ion. Although GO is plain, its size can reach several microns (this size is the order of $\AA$ in the case of AQSA or $\mathrm{PW}_{12} \mathrm{O}_{40}{ }^{3-}$ ). Its behavior seems to be more like a 3-D counter ion than a planar one. In bibliography, a decrease of conductivity was observed when using bulky counter ions [24]. However, bulky counter ions have the advantage that they remain retained in the polypyrrole structure due to their difficult diffusion [46].

\subsection{Electrochemical impedance spectroscopy (EIS) in solution}

Electrochemical impedance spectroscopy in solution was used to analyze the electrochemical behavior of the conducting fabrics.
The inset in Fig. 6b shows the equivalent electrical circuit used to fit the experimental data [47]. The equivalent electrical circuit is composed of:

- Ren: is a resistance that includes the electrolyte resistance (Re), the electronic resistance of the fabrics (Rf) and the electronic charge transfer resistance between the tweezers and the fabric (Rmfe).

- Rfsi: ionic charge transfer at the PES-PPy/GO interface corresponding to the counter ion exchange. In this case, since bulky GO acts as a negative counter ion immobilized in the PPy structure, the cations diffuse through the PPy/GO to produce the charge compensation [26].

- Cfsi: space charge capacitance at the PES-PPy/GO corresponding to the counter ion exchange.

- Rfsie: ion-electron charge transfer resistance at the PES-PPy/GO | solution interface with redox species.

- W: Warburg impedance due to counter-ion diffusion. W-R: diffusion resistance. $\mathrm{W}-\mathrm{T}: \mathrm{l}^{2} / \mathrm{D}(\mathrm{s})$, l: length of the diffusion layer, D: binary electron-ion diffusion coefficient. W-P: Warburg exponent.

Fig. 6a shows the Nyquist plots for the different conducting fabrics. In Fig. 6b the Nyquist plot has been magnified for better observation of the high frequency region. Fig. 6c shows the impedance modulus $|\mathrm{Z}|$ vs. frequency plot and Fig. 6d represents the -phase angle vs. frequency plot. In all the plots, the experimental data has been represented by dots and the fitted data has been represented by continuous lines. The most remarkable features are the following: As can be seen in Fig. 6b, there was a clear increase of the ionic charge transfer resistance at the PES-PPy/GO interface (Rfsi) as the GO content was increased. The other remarkable feature was the increase in the ion-electron charge transfer resistance (Rfsie) at the PES-PPy/GO textile/ solution interface with redox species when the GO content was increased. The increase in Rfsie indicates a lower electroactivity of the fabrics when the GO content increased. The different values of the fitted parameters can be observed in Table 3. Fig. $6 \mathrm{c}$ shows an increase of the impedance modulus $|\mathrm{Z}|$ at the lower frequencies with the increasing GO content, which indicates an increase of the diffusion electrical resistance when the GO content was increased. Fig. $6 \mathrm{~d}$ shows the Bode plot, where two time constants can be observed. The process at high frequencies $\left(>10^{2} \mathrm{~Hz}\right)$ is due to the space charge capacitance at the PES-PPy/GO corresponding to the counter ion exchange. The process at low frequencies $\left(10^{-1}\right.$ to $10^{2} \mathrm{~Hz}$ ) with -phase angle reaching nearly $45^{\circ}$ at $10^{-2} \mathrm{~Hz}$ is due to the Warburg diffusion. 


\subsection{Cyclic voltammetry}

Fig. 7a shows the voltammetric characterization of the PES-PPy/ GO (10\%) sample at different scan rates. As can be seen, the scan rate has an influence on the electrochemical response obtained. The charge transfer proceeds through the conducting polymer chains since PES is an insulating material. Only if low scan rates are used, the oxidation/reduction of PPy can be observed properly due to the slow kinetics of oxidation/reduction on the fabrics. Otherwise, a more resistive response is obtained as observed for higher scan rates. This type of behavior has been previously observed with this type of materials and is related to the slow electron transfer $[17,48]$. Yaghoubidoust et al. obtained PPy coated fabrics which showed more capacitive behavior at higher scan rates $\left(50 \mathrm{mV} \mathrm{s}^{-1}\right)$ although a resistive form was still obtained [49]. In this case, the authors previously deposited a GO layer on the fabrics and later synthesized the PPy layer, obtaining a bilayer coating. The GO was partially reduced and this could provide conductive pathways that accelerate the electron transfer.

Fig. 7b shows the comparison of the voltammograms of the conducting fabrics obtained with different GO contents. The scan rate of $1 \mathrm{mV} \mathrm{s}^{-1}$ was used to compare the results. As can be seen, as the GO content increases, there is a decrease of electroactivity since lower currents and lower electrical charge are obtained. The increase in the GO content leads to a decrease in the electroactivity. This result is in accordance to the results obtained by means of XPS and EIS.

\subsection{Scanning electrochemical microscopy (SECM)}

The electroactivity of the different PES-PPy/GO and PPy/GO samples was tested by means of SECM with feedback mode. The
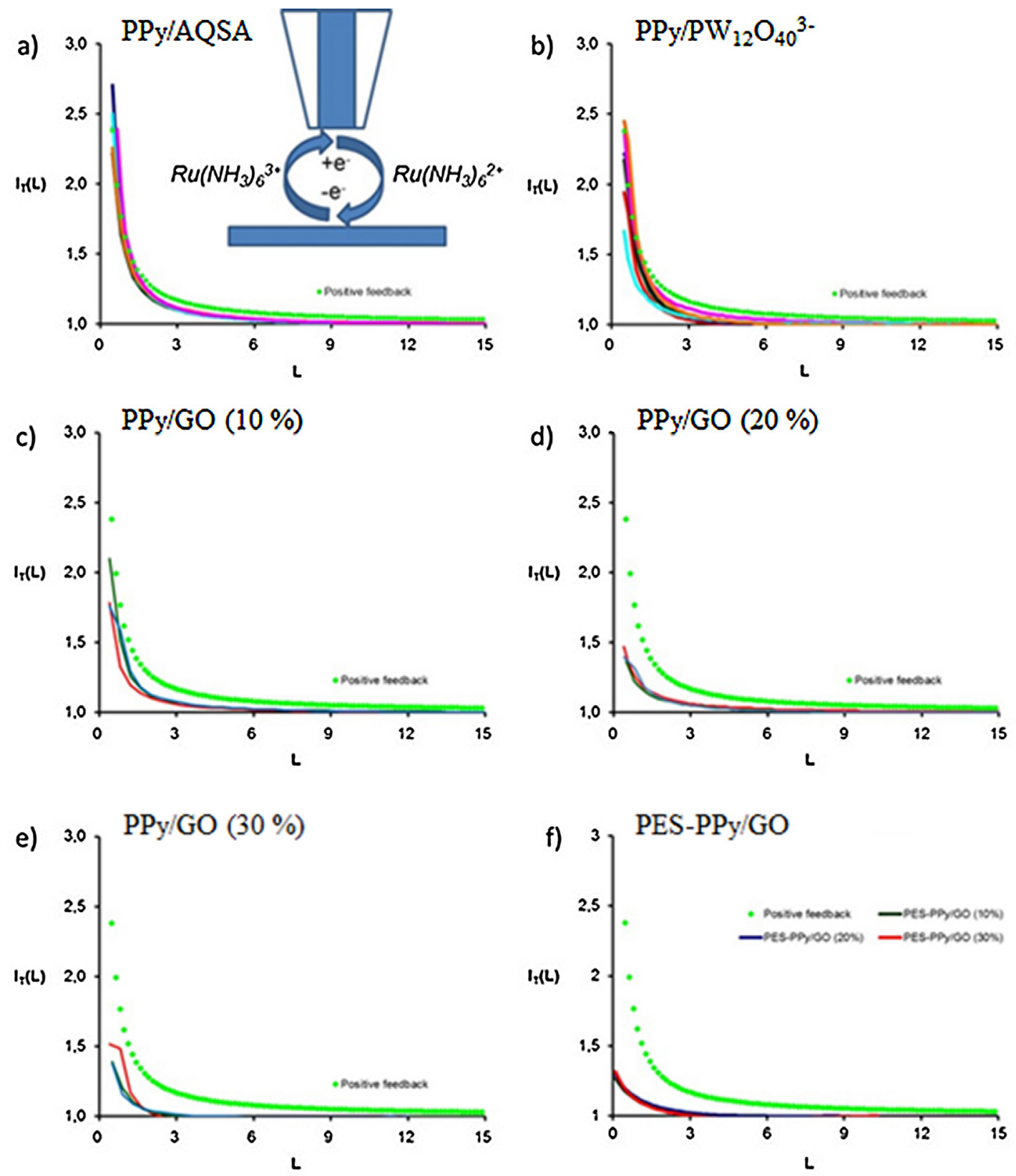

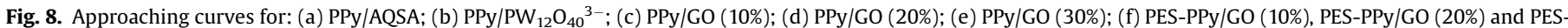

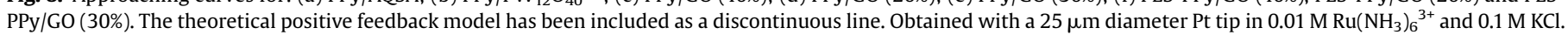

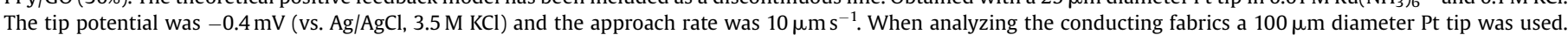


reduction current when the oxidized form of the redox mediator $(\mathrm{Ox})$ is reduced (Red) is measured as the microelectrode approaches the surface to be studied. The potential of the microelectrode was fixed at $-0.4 \mathrm{~V}$, where the oxidized form of the redox mediator $\left(\mathrm{Ru}\left(\mathrm{NH}_{3}\right)_{6}{ }^{3+}\right)$ is reduced $\left(\mathrm{Ru}\left(\mathrm{NH}_{3}\right)_{6}{ }^{2+}\right)$ on the microelectrode's surface at a diffusion controlled rate $\left(i_{\infty}\right)$ (Fig. S6a). The measured current is defined as $i_{\infty}=4 \times n \times \mathrm{F} \times D \times$ $C \times a$, where $n$ is the number of electrons, $\mathrm{F}$ is the Faraday constant, $D$ is the diffusion coefficient, $C$ is the bulk concentration of the redox mediator and $a$ is the radius of the microelectrode tip.

Supplementary material related to this article found, in the online version, at http://dx.doi.org/10.1016/j.synthmet.2015. 03.014.

In approach curves, the normalized reduction current registered at the microelectrode $(I)$ is represented vs. the normalized distance $(L)$. The normalized current is defined as follows: $I=i / i_{\infty}$ where " $i$ " is the current measured at the microelectrode tip and $i_{\infty}$ is the diffusion current defined above. The normalized currents depend on $R G$ ( $R G=R g / a$, where $\mathrm{Rg}$ is the radius of the insulating glass surrounding the Pt tip of radius " $a$ ") and the normalized distance $L$; where $L=d / a$ ( $d$ is the microelectrode-substrate separation). The RG of the microelectrode used in this work was $\mathrm{RG} \geq 20$.

Depending on the distance between the microelectrode and the substrate and the electroactivity of the substrates, different situations can happen:

- If the microelectrode is far away from the substrate, the diffusion current is measured $\left(i_{\infty}\right)$. The normalized current $(I)$ is equal to 1 .

- If the microelectrode approaches a non-conductive substrate, there is a hindrance to the diffusion of Ox species. The surface of the sample is not able to regenerate (oxidize) the reduced form of the redox mediator (Red), hence there is a decrease in the reduction current on the surface of the microelectrode, $i<i_{\infty}$. This situation is known as negative feedback [50] and is characterized by $I<1$.

- On the other hand, if the substrate is conductive, when the microelectrode approaches the surface of the sample, there is an increase in the oxidized redox species flux (Ox). The surface potential of the sample is able to regenerate (oxidize) the redox mediator. This causes an increase in the current measured on the microelectrode, $i>i_{\infty}$. This case is known as positive feedback [50] and is characterized by $I>1$.

Experimental approach curves were compared with a theoretical one for positive feedback model, according to Eq. (1). According to Rajendran and Ananthi [51], Pade's approximation gives a close and simple equation with less relative error for all distances and valid for $R G>10$. The approximate formula of the steady-state normalized current assuming positive feedback for finite conductive substrate together with finite insulating glass thickness is:

$I_{T^{c}}=\left[\frac{1+1.5647 / L+1.316855 / L^{2}+0.4919707 / L^{3}}{1+1.1234 / L+0.626395 / L^{2}}\right]$

Fig. 8a and b shows the approach curves for PPy doped with an organic counter ion (AQSA) and an inorganic counter ion $\left(\mathrm{PW}_{12} \mathrm{O}_{40}{ }^{3-}\right)$, respectively. More positive values of positive feedback were achieved in the case of AQSA (in the range 2.3-2.7). This indicates that PPy doped with AQSA is slightly more electroactive than when doped with the inorganic counter ion $\mathrm{PW}_{12} \mathrm{O}_{40}{ }^{3-}$ (in the range 1.7-2.4). The curve for the positive feedback model is also presented for comparison as a discontinuous line in the different graphics, and as can be seen, the experimental data adjusts to the theoretical model. A comparative of electroactivity measured by SECM of PPy depending on the nature of the counter ion had not been established in bibliography to the best of our knowledge. Fig. $8 \mathrm{c}$-e shows the different approach curves obtained for PPy/GO pellets doped with the different GO contents (10, 20 and 30\%), respectively. All the samples presented positive feedback indicating the electroactivity of the composites. The highest electroactivity was obtained for the sample with the lowest GO content (10\%). The values of positive feedback obtained were in the range 1.8-2.1. When the GO content was increased, there was a decrease of the electroactivity and the positive feedback values were reduced to values of 1.4-1.5. However, the electroactivity was clearly reduced when comparing the results to the organic and inorganic counter ions. The electroactivity followed this order: $\mathrm{PPy} / \mathrm{AQSA}>\mathrm{PPy} / \mathrm{PW}_{12} \mathrm{O}_{40}{ }^{3-}>$ $\mathrm{PPy} / \mathrm{GO}$. The size of the counter ion has a clear effect on the electroactivity of the PPy samples. The higher the size of the counter ion, the lower the electroactivity is.

Fig. $8 \mathrm{f}$ shows the SECM approach curves of the PES fabrics coated with PPy/GO with the different GO contents (10, 20 and $30 \%$ ). As can be seen, there was not a substantial variation in the positive feedback values and a value around 1.3 was obtained for all the fabrics. The decrease in the value of positive feedback of the conductive fabrics when compared with the pellets could be related to the existence of gaps between the fibers of the fabrics. In the gaps, there is no conductive material and the positive feedback value decreased in comparison to the continuous and flat surface of the PPy/GO pellets. The approach curves for PES fabrics coated with PPy/AQSA and PPy/ $\mathrm{PW}_{12} \mathrm{O}_{40}{ }^{3-}$ followed the same trend as the pellets. The respective approach curves for both types of fabrics can be found in bibliography $[17,18]$.

The redox mediator $\left(\mathrm{Ru}\left(\mathrm{NH}_{3}\right)_{6}{ }^{3+/ 2+}\right.$ is an outer sphere redox mediator and is not sensitive to surface oxides [52], thus, it is not able to detect the presence of surface oxides on the GO surface. In contrast, the redox mediator $\mathrm{Fe}^{3+/ 2+}$ is sensitive to surface oxides, this is why it was also used to test the electroactivity of the PES-PPy/GO fabrics. In this case, the Pt tip was polarized at $0.1 \mathrm{~V}$ where $\mathrm{Fe}^{3+}$ is reduced to $\mathrm{Fe}^{2+}$ at diffusion controlled rate (Fig. S6b). Fig. 9 shows the approach curves for

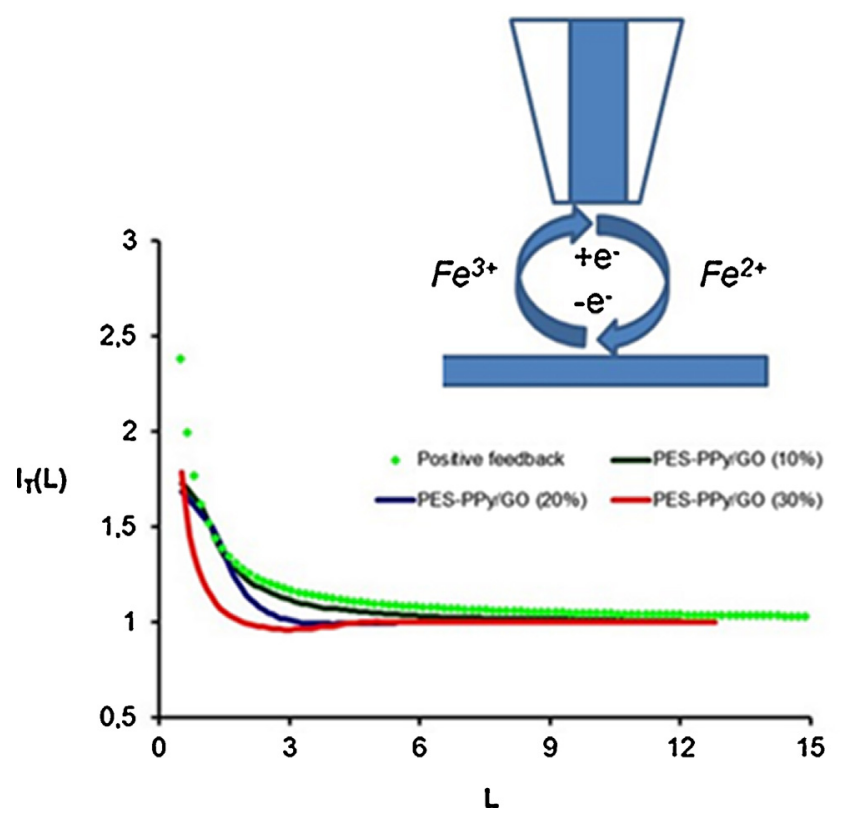

Fig. 9. Approaching curves for PES-PPy/GO (10\%), PES-PPy/GO (20\%) and PES-PPy/ GO (30\%). The theoretical positive feedback model has been included as a discontinuous line. Obtained with a $100 \mu \mathrm{m}$ diameter Pt tip in $0.01 \mathrm{M} \mathrm{Fe}^{3+}$ and $0.5 \mathrm{M}$ $\mathrm{H}_{2} \mathrm{SO}_{4}$ solution. The tip potential was $-0.1 \mathrm{~V}(\mathrm{vs} \mathrm{Ag} / \mathrm{AgCl})$ and the approach rate was $10 \mu \mathrm{ms}^{-1}$. 
the fabrics coated with PPy and different GO contents. Differences in the positive feedback degree between the different fabrics were not observed, and similar curves were obtained independently of the GO content. However, an increase in the positive feedback value was observed. In this case values of positive feedback around 1.7-1.8 were achieved. This difference of positive feedback between the $\left(\mathrm{Ru}\left(\mathrm{NH}_{3}\right)_{6}{ }^{3+/ 2+}\right.$ and the $\mathrm{Fe}^{3+/ 2+}$ redox mediator (1.3 vs. $\left.1.7-1.8\right)$ can be attributed to the presence of GO in the PPy structure since the $\mathrm{Fe}^{3+/} \mathrm{Fe}^{2+}$ redox mediator is sensitive to surface oxides presence.

\section{Conclusions}

Polypyrrole doped with graphene oxide has been synthesized on polyester fabrics by chemical oxidation. This has been the first report using GO as counter ion in the production of conductive fabrics. Polypyrrole was doped with different GO contents (10, 20 and 30\%). The most remarkable fact was that conductivity and electroactivity of PES-PPy/GO could be tuned by varying the GO content in the synthesis solutions. The different chemical characterization techniques showed the formation of the PPy/ GO composite. In FTIR-ATR spectra, the different PPy bands appeared and the PES bands almost vanished indicating a good thickness of the PPy coating on the fabrics. The presence of a band at $1700 \mathrm{~cm}^{-1}$ corresponding to the stretching vibration of $\mathrm{C}=\mathrm{O}$ indicated the incorporation of GO as counter ion. EDX showed a good distribution of oxygen in the PPy/GO coatings which indicates a good distribution of GO in the composite. XPS measurements showed an increase in the oxygen content and in the oxidized groups as the GO content increased. A decrease in the doping level of PPy $\left(\mathrm{N}^{+} / \mathrm{N}\right)$ with the increasing GO content was also observed. Evidence for the incorporation of GO in the PPy's structure was also obtained from FESEM. The PPy/GO powders not fixed on the fibers showed the typical planar structure of GO coated with PPy in the form of globules.

The electrical properties measured by EIS, showed the increase in resistance/surface resistivity with the GO content. In general, a decrease in electroactivity was also observed as the GO content increased, as measured by EIS in solution and CV and SECM. For SECM measurements with the fabrics, similar values of positive feedback were obtained regarding the GO content. Another redox mediator, $\mathrm{Fe}^{3+} / \mathrm{Fe}^{2+}$ which is sensitive to surface oxides, confirmed the presence of $\mathrm{GO}$ in all the fabrics.

An organic (AQSA) and an inorganic counter ion $\left(\mathrm{PW}_{12} \mathrm{O}_{40}{ }^{3-}\right)$ were also used as counter ions to obtain composites with PPy and compare the results with those obtained for PPy/GO powders. When comparing the different counter ions used, the electroactivity followed this order: PPy/AQSA $>\mathrm{PPy} / \mathrm{PW}_{12} \mathrm{O}_{40}{ }^{3-}>\mathrm{PPy} / \mathrm{GO}$. The decrease of electroactivity can be attributed to the increasing size of the counter ion employed. However, bulky counter ions have the advantage that they remain retained in the polymer structure.

\section{Acknowledgements}

Authors wish to thank to the Spanish Ministerio de Ciencia e Innovación (contract CTM2011-23583) for the financial support. J. Molina is grateful to the Conselleria d'Educació, Formació i Ocupació (Generalitat Valenciana) for the Programa VALi+D Postdoctoral Fellowship. Andrea Zille (C2011-UMINHO-2C2T-01) acknowledges FCT funding from Programa Compromisso para a Ciência 2008, Portugal. XPS studies were performed at CEMUP (University of Porto, Portugal) facilities. Electron Microscopy Service of the UPV (Universitat Politècnica de València) is gratefully acknowledged for help with FESEM and EDX characterization.

\section{References}

[1] R.F. Service, Technology - electronic textiles charge ahead, Science 301 (5635) (2003) 909-911.

[2] A.R. Horrocks, B.K. Kandola, P.J. Davies, S. Zhang, S.A. Padbury, Developments in flame retardant textiles - a review, Polym. Degrad. Stab. 88 (1) (2005) $3-12$.

[3] M. Yu, Z.Q. Wang, H.Z. Liu, S.Y. Xie, J.X. Wu, H.Q. Jiang, et al., Laundering durability of photocatalyzed self-cleaning cotton fabric with $\mathrm{TiO}_{2}$ nanoparticles covalently immobilized, ACS Appl. Mater. Interfaces 5 (9) (2013) 3697-3703.

[4] Y. Shin, D.I. Yoo, K. Son, Development of thermoregulating textile materials with microencapsulated phase change materials (PCM). II. Preparation and application of PCM microcapsules, J. Appl.Polym. Sci. 96 (6) (2005) 2005-2010.

[5] A. Laforgue, Electrically controlled colour-changing textiles using the resistive heating properties of PEDOT nanofibers, J. Mater. Chem. 20 (38) (2010) 8233-8235.

[6] R.R. He, T.D. Day, M. Krishnamurthi, J.R. Sparks, P.J.A. Sazio, V. Gopalan, et al., Silicon $p-i-n$ junction fibers, Adv. Mater. 25 (10) (2013) 1461-1467.

[7] D. Graham-Rowe, Photonic fabrics take shape, Nat. Photonics 1 (1) (2007) 6-7.

[8] N.K. Vu, A. Zille, F.R. Oliveira, N. Carneiro, A.P. Souto, Effect of particle size on silver nanoparticle deposition onto dielectric barrier discharge (DBD) plasma functionalized polyamide fabric, Plasma Processes Polym. 10 (3) (2013) 285-296.

[9] J.O. Carneiro, V. Teixeira, J.H.O. Nascimento, J. Neves, P.B. Tavares, Photocatalytic activity and UV-protection of $\mathrm{TiO}_{2}$ nanocoatings on poly (lactic acid) fibres deposited by pulsed magnetron sputtering, J. Nanosci. Nanotechnol. 11 (10) (2011) 8979-8985.

[10] J.W. Lee, T. Mayer-Gall, K. Opwis, C.E. Song, J.S. Gutmann, B. List, Organotextile catalysis, Science 341 (6151) (2013) 1225-1229.

[11] Z. Li, G. Luo, F. Wei, Y. Huang, Microstructure of carbon nanotubes/PET conductive composites fibers and their properties, Composites Sci. Technol. $66(7-8)(2006)$ 1022-1029.

[12] X. Zhao, K. Hirogaki, I. Tabata, S. Okubayashi, T. Hori, A new method of producing conductive aramid fibers using supercritical carbon dioxide, Surf. Coat. Technol. 201 (3-4) (2006) 628-636.

[13] J. Molina, J. Fernandez, J.C. Ines, A.I. del Rio, J. Bonastre, F. Cases, Electrochemical characterization of reduced graphene oxide-coated polyester fabrics, Electrochim. Acta 93 (2013) 44-52.

[14] J. Molina, J. Fernandez, A.I. del Rio, J. Bonastre, F. Cases, Chemical and electrochemical study of fabrics coated with reduced graphene oxide, Appl. Surf. Sci. 279 (2013) 46-54.

[15] X. Li, P.Z. Sun, L.L. Fan, M. Zhu, K.L. Wang, M.L. Zhong, et al., Multifunctional graphene woven fabrics, Sci. Rep. (2012) 2012.

[16] J. Molina, A.L. del Rio, J. Bonastre, F. Cases, Chemical and electrochemical polymerisation of pyrrole on polyester textiles in presence of phosphotungstic acid, Eur. Polym. J. 44 (7) (2008) 2087-2098.

[17] J. Molina, J. Fernandez, A.I. del Rio, R. Lapuente, J. Bonastre, F. Cases, Stability of conducting polyester/polypyrrole fabrics in different $\mathrm{pH}$ solutions: chemical and electrochemical characterization, Polym. Degrad. Stab. 95 (12) (2010) 2574-2583.

[18] J. Molina, J. Fernandez, A.I. del Rio, J. Bonastre, F. Cases, Chemical, electrical and electrochemical characterization of hybrid organic/inorganic polypyrrole/ $\mathrm{PW}_{12} \mathrm{O}_{40}{ }^{3-}$ coating deposited on polyester fabrics, Appl. Surf. Sci. 257 (23) (2011) 10056-10064.

[19] J. Molina, A.L. del Rio, J. Bonastre, F. Cases, Electrochemical polymerisation of aniline on conducting textiles of polyester covered with polypyrrole/AQSA Eur. Polym. J. 45 (4) (2009) 1302-1315.

[20] J. Molina, A.I. del Rio, J. Bonastre, F. Cases, Influence of the scan rate on the morphology of polyaniline grown on conducting fabrics. Centipede-like morphology, Synth. Met. 160 (1-2) (2010) 99-107.

[21] D. Li, M.B. Muller, S. Gilje, R.B. Kaner, G.G. Wallace, Processable aqueous dispersions of graphene nanosheets, Nat. Nanotechnol. 3 (2) (2008) 101-105.

[22] Complete textile glossary, available from:. http://www.composites.ugent.be/ home_made_composites/documentation/ Illustrated_dictionary_of_fiber_and_textile_technology.pdf, 2001. (accessed 26.2.15.).

[23] J. Clavilier, The role of anion on the electrochemical behaviour of a $\{111\}$ platinum surface; an unusual splitting of the voltammogram in the hydrogen region, J. Electroanal. Chem. Interfacial Electrochem. 107 (1) (1979) 211-216.

[24] E. Hakansson, T. Lin, H.X. Wang, A. Kaynak, The effects of dye dopants on the conductivity and optical absorption properties of polypyrrole, Synth. Met. 156 (18-20) (2006) 1194-1202.

[25] J.B. Schlenoff, H. Xu, Evolution of physical and electrochemical properties of polypyrrole during extended oxidation, J. Electrochem. Soc. 139 (9) (1992) 2397-2401.

[26] C.Z. Zhu, J.F. Zhai, D. Wen, S.J. Dong, Graphene oxide/polypyrrole nanocomposites: one-step electrochemical doping, coating and synergistic effect for energy storage, J. Mater. Chem. 22 (13) (2012) 6300-6306.

[27] E. Romero, J. Molina, A.I. del Rio, J. Bonastre, F. Cases, Synthesis of PPy/ $\mathrm{PW}_{12} \mathrm{O}_{40}{ }^{3-}$ organic-inorganic hybrid material on polyester yarns and subsequent weaving to obtain conductive fabrics, Text. Res. J. 81 (14) (2011) 1427-1437.

[28] S.P. Lim, A. Pandikumar, Y.S. Lim, N.M. Huang, H.N. Lim, In-situ electrochemically deposited polypyrrole nanoparticles incorporated reduced graphene oxide as an efficient counter electrode for platinum-free dye-sensitized solar cells, Sci. Rep. 4 (2014) Article no. 5305. 
[29] X. Shen, X.Y. Lin, N. Yousefi, J.J. Jia, J.K. Kim, Wrinkling in graphene sheets and graphene oxide papers, Carbon 66 (2014) 84-92.

[30] Y.L. Zhong, Z. Tian, G.P. Simon, D. Li, Scalable production of graphene via wet chemistry: progress and challenges, Mater. Today 18 (2) (2015) 73-78.

[31] S. Bose, T. Kuila, M.E. Uddin, N.H. Kim, A.K.T. Lau, J.H. Lee, In-situ synthesis and characterization of electrically conductive polypyrrole/graphene nanocomposites, Polymer 51 (25) (2010) 5921-5928.

[32] P. Lisboa, D. Gilliland, G. Ceccone, A. Valsesia, F. Rossi, Surface functionalisation of polypyrrole films using UV light induced radical activation, Appl. Surf. Sci. 252 (13) (2006) 4397-4401.

[33] Y.S. Lim, Y.P. Tan, H.N. Lim, W.T. Tan, M.A. Mahnaz, Z.A. Talib, et al., Polypyrrole graphene composite films synthesized via potentiostatic deposition, J. Appl. Polym. Sci. 128 (1) (2013) 224-229.

[34] D.B. Cairns, S.P. Armes, M.M. Chehimi, C. Perruchot, M. Delamar, X-ray photoelectron spectroscopy characterization of submicrometer-sized polypyrrole - polystyrene composites, Langmuir 15 (23) (1999) 8059-8066.

[35] C. Malitesta, I. Losito, L. Sabbatini, P.G. Zambonin, New findings on polypyrrole chemical structure by XPS coupled to chemical derivatization labelling, J. Electron Spectrosc. Relat. Phenom. 76 (1995) 629-634.

[36] D. Yang, A. Velamakanni, G. Bozoklu, S. Park, M. Stoller, R.D. Piner, et al., Chemical analysis of graphene oxide films after heat and chemical treatments by X-ray photoelectron and micro-Raman spectroscopy, Carbon 47 (1) (2009) $145-152$.

[37] P. Liu, Y. Huang, L. Wang, W. Zhang, Synthesis and excellent electromagnetic absorption properties of polypyrrole-reduced graphene oxide- $\mathrm{Co}_{3} \mathrm{O}_{4}$ nanocomposites, J. Alloys Compd. 573 (2013) 151-156.

[38] J. Wang, Y. Xu, J. Zhu, P. Ren, Electrochemical in situ polymerization of reduced graphene oxide/polypyrrole composite with high power density, J. Power Sources 208 (2012) 138-143.

[39] D. Zhang, X. Zhang, Y. Chen, P. Yu, C. Wang, Y. Ma, Enhanced capacitance and rate capability of graphene/polypyrrole composite as electrode material for supercapacitors, J. Power Sources 196 (14) (2011) 5990-5996.

[40] Z.-D. Huang, R. Liang, B. Zhang, Y.-B. He, J.-K. Kim, Evolution of flexible 3D graphene oxide/carbon nanotube/polyaniline composite papers and their supercapacitive performance, Composites Sci. Technol. 88 (2013) 126-133.
[41] S. Zhang, Y. Shao, J. Liu, I.A. Aksay, Y. Lin, Graphene-polypyrrole nanocomposite as a highly efficient and low cost electrically switched ion exchanger for removing $\mathrm{ClO}_{4}{ }^{-}$from wastewater, ACS Appl. Mater. Interfaces 3 (9) (2011) 3633-3637.

[42] B. Saoudi, N. Jammul, M.M. Chehimi, A.S. Jaubert, C. Arkam, M. Delamar, XPS study of the adsorption mechanisms of DNA onto polypyrrole particles, Spectrosc. Int. J. 18 (4) (2004) 519-535.

[43] M. Ignatova, S. Voccia, S. Gabriel, B. Gilbert, D. Cossement, R. Jèrôme, et al., Stainless steel grafting of hyperbranched polymer brushes with an antibacterial activity: synthesis, characterization, and properties, Langmuir 25 (2) (2009) 891-902.

[44] J. Zheng, H.-T. Liu, B. Wu, C.-A. Di, Y.-L. Guo, T. Wu, et al., Production of graphite chloride and bromide using microwave sparks, Sci. Rep. (2012) 2012.

[45] T. Textor, B. Mahltig, A sol-gel based surface treatment for preparation of water repellent antistatic textiles, Appl. Surf. Sci. 256 (6) (2010) 1668-1674.

[46] K.G. Neoh, T.T. Young, E.T. Kang, T. Kang, Structural and mechanical degradation of polypyrrole films due to aqueous media and heat treatment and the subsequent redoping characteristics, J. Appl. Polym. Sci. 64 (3) (1997) 519-526.

[47] J. Bonastre, J. Molina, A.I. del Rio, J.C. Galvan, F. Cases, Study of the electrical properties of novel hybrid organic-inorganic conducting textiles of polypyrrole-phosphotungstate-polyester using electrochemical impedance spectroscopy, Synth. Met. 161 (17-18) (2011) 1958-1965.

[48] G.J. Liang, L.G. Zhu, J. Xu, D. Fang, Z.K. Bai, W.L. Xu, Investigations of poly (pyrrole)-coated cotton fabrics prepared in blends of anionic and cationic surfactants as flexible electrode, Electrochim. Acta 103 (2013) 9-14.

[49] F. Yaghoubidoust, D.H.B. Wicaksono, S. Chandren, H. Nur, Effect of graphene oxide on the structural and electrochemical behavior of polypyrrole deposited on cotton fabric, J. Mol. Struct. 1075 (2014) 486-493.

[50] P. Sun, F.O. Laforge, M.V. Mirkin, Scanning electrochemical microscopy in the 21st century, Phys. Chem. Chem. Phys. 9 (7) (2007) 802-823.

[51] L. Rajendran, S.P. Ananthi, Analysis of positive feedback currents at the scanning electrochemical microscope, J. Electroanal. Chem. 561 (1-2) (2004) $113-118$.

[52] R.L. McCreery, Advanced carbon electrode materials for molecular electrochemistry, Chem. Rev. 108 (7) (2008) 2646-2687. 